\title{
Antologías y crítica literaria. Entre el chiste y el chisme (en torno a una carta de Roberto Bolaño)
}

\author{
Soledad Bianchi \\ Universidad de Chile
}

Un escrito que me envió Roberto Bolaño será mi punto de partida para relacionar, muy someramente, antologías y crítica literaria, complicados asuntos de los que tanto se ha reflexionado. Tan complejos, me parecen estos quehaceres, que no sé si es uno o si son dos, pues me pregunto si al armar una antología no se elabora, también, una -tácita o velada- crítica literaria o, mejor: si la primera no responde a una segunda, silenciosa. Dejo esta duda en suspenso y coloco, además, estas materias en una disyuntiva tan especial como el chiste y el chisme, todo presente, como se verá, en el mensaje ya señalado.

Para comenzar, algunas explicaciones: con Bolaño sostuvimos una afectuosa y extensa correspondencia, y yo recibí, aproximadamente, unas cincuenta cartas, en muchas de estas él compartía sus preocupaciones respecto del dificultoso -y fascinante- proceso de un joven que tenía la certeza absoluta y el compromiso personal de llegar a ser escritor, siendo totalmente consciente del esfuerzo que le significaría y de los riesgos y obstáculos a enfrentar... y superar. Hace un tiempo encontré que la primera, del 17 de agosto de 1979, era mía: me dirigía a él, pidiéndole colaboraciones para Araucaria, una revista cultural del Partido Comunista de Chile, que apareció en los tiempos del exilio, durante la dictadura cívico-militar, que se prolongó entre el 11 de septiembre de 1973 y marzo de 1990. Casi una síntesis del destierro por la dispersión geográfica con que funcionaba: Araucaria era publicada en España, su Director residía en la Unión Soviética, sus colaboradores -independientes o militantes, sin restricción partidaria ninguna- íbamos desde Chile hasta los cincuenta y tantos países donde nos desperdigamos los chilenos, y su Consejo de Redacción, de seis o siete miembros, al que pertenecí por algunos años, sesionaba en Francia. Yo había leído textos de Bolaño, y de su amigo, Bruno Montané, en la revista cubana Casa de las Américas, y así se lo manifestaba. Desde ese momento establecimos un intercambio constante, aunque no siempre regular, que se fue distanciando e interrumpiendo con mi regreso definitivo a Chile en 1987.

A diferencia de la mayoría de sus correos, que eran manuscritos, estas dos páginas están escritas a máquina, con algunos pocos agregados a mano: entre ellos, la ubicación, espacial y temporal: "Blanes, enero de 1993". Yo diría que, en sus dos párrafos (mecanografiados), pueden distinguirse tres partes, y las tres se relacionan con poesía. La tercera, y última, es la más personal y biográfica: Bolaño cuenta que abandonó la "dirección literaria" de una editorial porque "...A estas alturas de mi vida o publico lo que quiero o me dedico a escribir lo mío, que ya bastante trabajo me da...", dice. Y, entre otros intereses, lo que deseaba imprimir iba desde "clásicos del siglo de Oro" hasta poetas más o menos actuales: "chilenos" (no designa ninguno), 
peruanos (Enrique Verástegui), mexicanos (Orlando Guillén), españoles (Carlos Edmundo de Ory).

Me centraré en la comunicación epistolar mencionada, pese a que refiere a un libro mío, pues considero muy creativo, ingenioso y sutil, el modo cómo este literato dice, sin decir directamente, o no dice, diciendo de una manera lateral, es decir, preteriza (la preterición -según María Moliner- es una "figura retórica que consiste en decir que se omite una cosa con lo cual, precisamente, se la menciona"). Esta oblicuidad es, pienso, yo, su forma de hacer crítica literaria, en este caso y para esta ocasión. Sin declarar su título, el remitente está indicando a Viajes de ida y vuelta: poetas chilenos en Europa (un panorama), que me había solicitado el narrador José Leandro Urbina, hacia 1985, a nombre de las canadienses Ediciones Cordillera, promovidas por algunos escritores chilenos, exiliados y residentes en ese país. En 1986, yo había finalizado la selección de (pocos) textos de cada uno de los treinta y seis autores, finalmente escogidos, pero por múltiples dificultades, el volumen fue publicado seis años después, en 1992 y en Chile, con el sello "Ediciones Documentas / Ediciones Cordillera", pero ni siquiera circuló a causa de la quiebra de la primera.

Bolaño observa: "Querida Soledad: Comienzo por el último párrafo de tu carta. ¿Cómo podría yo opinar de forma negativa sobre un libro tuyo, una antología tuya, una recopilación de Soledad Bianchi en donde soy incluido? ¡Pero si tú eres mi Hernán Cortés! iTú eres mi Pizarro y mi Almagro! .......". De sus dichos puede deducirse que esta NO le convence al NO estar totalmente de acuerdo con mis elecciones. Por lo demás, años antes, en un mensaje no fechado, que responde a uno mío del 10 de agosto de 1986, él ya había manifestado su disconformidad con mi voluntad de desplegar un amplio conjunto, casi un muestrario, aunque selectivo: "... Lo que a mí me intriga -señala- es a quiénes [sic] vas a incluir, porque, sin ánimo de ofender a nadie, yo solo sé de contadísimos poetas chilenos en Europa. Por supuesto, hay cientos de hijitos de su papá deambulando por universidades del viejo continente, pero... [sic] confío en tu criterio y desde ya tengo ganas de leer el libro. ...". Su misiva subsiguiente -esta, de enero de 1993- responde a una mía que no encontré donde, según dice él -y no me cabe duda que así debe ser-, yo le solicitaba la juzgara. Roberto Bolaño posterga su respuesta, haciendo algunos rodeos que llevan a la hilaridad cuando me identifica, por ejemplo, con varios conquistadores españoles: ¿por ser lectora temprana de sus cuentos y poemas inéditos de años anteriores, acaso? No obstante, puede reconocerse cierta ambigüedad en la comparación, a causa de las tropelías, derrotas, conflictos, que caracterizaron el actuar de estos soldados aventureros. Aparte lo anterior, indicar a estos personajes significa, todavía, una suerte de resonancia del apelativo por sus "viajes de ida y vuelta". En esa misma correspondencia de 1986, apunta (a mano): "...Me parece muy bien tu título, se entiende y todo eso, aunque puede interpretarse como una visión antropocentrista (¿se dice así?) de Europa. Los viajes de ida y vuelta se prestan a confusiones. ...".

Bolaño continúa posponiendo "opinar de forma negativa" cuando se detiene en la imagen de "la portada" e inventa toda una historia -de vehículos y sus rastros- que evidencia su calidad de narrador innato, enfatizada por 
la incorporación y las reflexiones del ficticio Bibiano Macaduck, uno de los personajes de "Patria", de Sepulcros de Vaqueros (2017), en ese monólogo o en esta suerte de conversación motivada por el hecho real y palpable del volumen antológico impreso. Por lo demás, las marcas de los coches referidos -un "Impala" y un jeep "Willy"- aparecerán, con posterioridad, en Los detectives salvajes -un modelo de otro año, eso sí- y en "El gaucho insufrible", respectivamente. Como "... un poco errático en su ruta, o juguetón, ..." se considera el trayecto del segundo auto: ¿sería excesivo aplicarlo al de la seleccionadora en sus elecciones presentes y, en consecuencia, a la antología?

Habría mucho que agregar, pero solo transcribo otra de sus irónicas preocupaciones: "...¿Dios mío, es que piensas convertirte en el [sic] Alone del final del siglo? ...". En esta consulta (retórica) alude al controvertido hombre de letras chileno, colaborador habitual del diario El Mercurio, quien: "Desde su crónica pontificaba, descubriendo autores noveles o condenando a quienes no le parecían merecer el aprecio de la opinión pública. Su poder llegó a ser tal (y duró tanto tiempo) que un libro se vendía o no de acuerdo al juicio de Alone" (Wikipedia). En 1935, Hernán Díaz Arrieta (1891-1984), con su seudónimo "de pluma": Alone, había publicado: Las cien mejores poesías chilenas. Creo que su protagonismo inquieta de tal modo al literato contemporáneo que, en su novela Nocturno de Chile (2000), lo transforma en figura fundamental. En ella: "...Farewell, el pope de la crítica literaria nacional, ... se hunde en una vejez balbuceante y perpleja, ..." (contratapa). Fuera del chiste, ¿qué se propondría Roberto Bolaño al imaginar esa curiosa proximidad entre Alone y yo?, ¿o sería solo un impulso o una chispa para una nueva ficción?

Y Bolaño mantiene el (supuesto) misterio y el suspenso, sin puntualizar ni calificar, uno a uno, ni los poemas ni a los escritores elegidos, centrándose, en cambio, en mí y mi tarea de antologadora que él ya conocía pues, en 1983, yo había publicado: Entre la lluvia y el arcoiris (Antología de jóvenes poetas chilenos. Ediciones del Instituto para el Nuevo Chile) -que estaba finalizada desde 1980- en la que él aparecía, tanto en escritos individuales como en otros "a dos manos", junto con Bruno Montané, acompañados de otros catorce autores. A diferencia del volumen de 1992, que se proponía evidenciar un amplio horizonte, el de los "poetas chilenos en Europa", el anterior era, más bien, un corte en el vasto campo de la lírica chilena producida, por lo general, con posterioridad al golpe cívico-militar, por algunos creadores inéditos o que recién comenzaban, representados con una mayor cantidad de textos y que, sin barreras geográficas, podían residir en Chile o en el extranjero, negándome a separar entre "dentro" y "fuera" (dicotomía tan cara a la dictadura para dividir entre "buenos" y "malos chilenos").

Alone y sus opciones literarias -como "afinidades electivas", se les identifica en Nocturno de Chile- le sirven a Bolaño para recordar a algunos artistas, y a partir de la simpatía del viejo crítico por Neruda y su actitud contraria, y beligerante, hacia De Rokha, imagina tensiones y contiendas tan extremas que lo llevan a concluir: "... Todas esas historias [de Alone y los dos "vates"], [son] tan parecidas al duelo en el OK Corral...". Y, tras fantasear con un Huidobro-pistolero, a quien, quizá por su vocación de polemista, no siempre exitoso, advierte como un pésimo pistolero, remata, clausurando 
esta sección epistolar: "...Ya puesto, ahí va el reparto de la película". No creo casual que antes de compartirlo, Bolaño haya mencionado ya, a tres de los llamados "cuatro grandes" de la poesía chilena ( $y$, más adelante, los volverá a incorporar).

"...Ya puesto, ahí va el reparto de la película"., escribe el narrador, repito, cerrando y abriendo tramos: luego, inicia esta segunda -y última- parte con un inventario de nombres de poetas chilenos, a quienes percibe como actores de una película de vaqueros, con sus correspondientes roles. A mi modo de ver, este elenco cinematográfico, tan heterogéneo y letrado, más que como una simple enumeración, más que una "poética del 'todo está aquí"' y una "poética del 'etcétera'" (Umberto Eco: El vértigo de las listas), podría leerse como sinónimo de antología pues, a mi entender, Roberto Bolaño responde a Viajes de ida y vuelta con otra, de su factura. Y si, en primera instancia, acercar la poesía a las películas del Oeste -género, como se sabe, muy codificado- pareciera solo un ejercicio humorístico, y que hay momentos aleatorios y difíciles de elucidar, estimo que, en muchas ocasiones, esta selección trasciende la casualidad y sus afectos, obedeciendo a criterios muy pensados. Precisamente, no creo fortuito que Gabriela Mistral encabece la nómina, siendo quien faltaba para completar la (habitual) cifra de "cuatro" cuando se le une y reúne con Huidobro, De Rokha y Pablo Neruda. Tal vez haya, aquí, una apropiación -irónica o no- de ese lugar común tan recalcado que inmoviliza a "los cuatro grandes de la poesía chilena", estereotipándolos, con un número y en un número, sin aportar nada al conocimiento de su poesía. Todavía más, resulta muy destacable que sea ella la introductora, si se tiene en cuenta que, en 1935, estando en plena producción, fue excluida de la decena de aceptados en la Antología de la Poesía Chilena Nueva, al considerársele poco innovadora: "trasnochada", dice Volodia Teitelboim, uno de los editores, junto con Eduardo Anguita, ambos autoantologados. ¿Habrá querido Bolaño reparar la injusticia de la ausencia, colocándola en primer lugar, y como "La jefa de la caravana de colonos"?

Es necesario aclarar que la lista antológica se limita a nombrar a treinta y seis autores (ila misma cantidad de los elegidos por mí!), sin aludir jamás a sus producciones poéticas ni en títulos ni, menos, en comentarios o análisis. Habría que conocer al dedillo y al detalle las biografías de los escritores, y sus escritos y escrituras, para saber si, efectivamente, los papeles otorgados les corresponden: ¿por qué, por ejemplo, Humberto Díaz-Casanueva sería "El médico borrachín" o "Un indio y su perro" corresponderían a: "Floridor Pérez y Floridor Pérez"?, ¿será por algún rasgo de sus vidas o de sus trabajos escriturales? Empero, en particular: "Las putas del saloon algunas nobles damas de la poesía chilena de los cincuenta y sesenta" es, para mí, un apodo totalmente inexplicable por su fuerte carga irónica y machista. Tal vez "Las putas del saloon" sean personajes infaltables en una película de vaqueros y Bolaño quiso hacer un chiste, pero al utilizar cierto lenguaje y cierto tono, a los que añade la omisión de nombres de las poetas, resultó un "chiste de mal gusto" pues las connotaciones se extreman y la referencia se vuelve despectiva y transforma a las escritoras en fantasmas inexistentes, y la misma Violeta Parra, citada arriba, está ahí como para desmentirlo. Y podría indicarse a Eliana Navarro, Delia Domínguez, Stella Díaz Varín, Eugenia Echeverría, Cecilia Vicuña, y muchas otras. 
Siempre quedará la duda, entonces, si en el criterio o los criterios utilizados para calificar y clasificar, primaron las historias que rodeaban al / a la poeta o si fue su quehacer literario o, simplemente, la simpatía personal (así: a Enrique Lihn, uno de sus grandes admirados, lo considera: "El cowboy más rápido y guapo del pueblo..."). Sea lo que sea, podría considerarse un modo íntimo y clandestino de practicar la crítica literaria.

Mi desconocimiento me lleva a sospechar que, en algunos casos, la etiqueta identificatoria de los actores-personajes podría ser intercambiable. En otros, sin embargo, es de absoluta pertinencia y claridad: que "Pablo Neruda" sea ""El dueño del rancho y mayor ganadero de la región" no sorprende: el apodo asume su figura e imagen, y las acepta, manteniéndolo en el importante lugar que ocupa -como persona y como poeta- dentro de la cultura chilena y de su canon lírico. Divisar a "Raúl Zurita" como "El Predicador" tampoco parece tan inconveniente: se atienda a sectores de su poesía o al tono y melodía de su lectura. De todos modos, es indiscutible que Bolaño (de)muestra un inmenso dominio del universo de las películas de vaqueros, sus personajes, situaciones y ambiente y, una vez más, como acostumbra en muchos de sus textos, evidencia su proclividad por repertorios tan variados que hacen ver su erudición en aspectos y temáticas muy disímiles y de muy diversos rangos.

La desnuda enumeración, con muy escasos comentarios, va creando un ritmo, un cierto movimiento que colabora a imaginar la locación -nada estática- de un pueblo del Oeste de Estados Unidos, con sus habitantes, circunstancias y entorno, siempre presentes en una película de vaqueros: "la maestra de escuela", "'el cowboy", los "pistoleros", el "indio", "el sepulturero", el "sheriff", el "gambusino", "El coronel del destacamento del $7^{\circ}$ de Caballería", "colonos", "Las putas del saloon", "el jugador", etc.; "taberna", "rancho", "tribu", "caravana", etcétera.

Y esta singular antología continúa sorprendiendo pues "Alonso de Ercilla: El viejo periodista y DUEÑO DE LA IMPRENTA [sic]" se encuentra veinticinco menciones más tarde que su inauguradora, "Gabriela Mistral: La jefa de la caravana de colonos". Ya se sabía que la selección no era cronológica porque "Carlos Pezoa Véliz: El guía de la caravana" ("Nuestro primer poeta nacional, cronológicamente hablando", según el crítico Jaime Concha), mayor que ella, es convocado después, y porque las fechas de nacimiento -nunca informadas- no se imponían como criterio ordenador. Al citar a Ercilla -"Inventor de Chile", lo apellidó Neruda-, y al no conocerse un comienzo poético en mapudungun, se está en los verdaderos inicios pues se invoca al origen de la poesía en Chile. Podría creerse que entre este español del siglo XVI y Bolaño (el último de los escritores a los que alude) se entregará un panorama lírico de cuatro siglos, abarcando toda la poesía chilena; empero, la mirada del joven solo se detiene en "El viejo periodista y DUEÑO DE LA IMPRENTA" para desplazarse, veloz, a su época, al siglo XX, y a sus colegas, antecedentes y coetáneos, sucesores de Ercilla, como él mismo y quienes los seguirán. Estas vistas amplias y rápidas mudanzas parecen explicarse por ser características del mismo observador: "¿Y cuál es mi papel?, te preguntarás" -(me) explica con mucho humor, con una comicidad que quiebra la (aparente) altanería del inicio de la comparación-: "Como BAUDELAIRE [sic], yo soy una nube, una 
nube delgada, afilada que pasa por la gran pradera. O bien una lagartija que toma sol en el tejado del salón. O el chino de la lavandería china. Sí señol Chi Huan cuidal de su pistola y de su dinelo podel bañalse con confianza. ¿Pepitas de olo? ¿Qué sel pepitas de olo? Yo tenel un poco de opio señol pase pol aquí sin miedo".

Salvo porque no están ni "Violeta Parra: La dueña de la taberna", cuya presencia -en esta selección- sobresale, considerando, sobre todo, la demora de la crítica para estimarla; ni un poeta secundario, Premio Nacional durante la dictadura, ni Floridor Pérez, ni tampoco escritores jóvenes, como: Rodrigo Lira ("El chico ayudante del sepulturero"), Juan Luis Martínez ("El pagador de la Wells Fargo"), Raúl Zurita ("El predicador"), Diego Maquieira ("El huerfanito rebelde y malcriado"), Gonzalo Muñoz y Bruno Montané ("dos amigos del huerfanito rebelde..."), cercanos a la edad del antologador, cuyas publicaciones surgen más tarde, creo reconocer que los puntos de partida para elaborar esta recopilación serían: la Antología de la poesía chilena contemporánea, que Alfonso Calderón editó en 1970 (Editorial Universitaria-Cormorán) para los autores más conocidos, y 33 nombres claves de la actual poesía chilena, realizada por la Escuela de Santiago, en 1968, y aparecida en Orfeo. Revista de poesía y teoría poética No 33-38, para algunos de los autores más secretos y menos difundidos: Gustavo Ossorio ("un indio muerto"), Omar Cáceres o Jorge Cáceres, incorporados, imagino, con la voluntad cierta de flexibilizar el canon.

Como sabemos, en las películas del Oeste, la frontera tiene un lugar determinante que marca y divide territorios y personajes. Entonces, frente a este "ejercicio" que hace Bolaño, es posible preguntarse si se proponía solo un juego (de)mostrar sus conocimientos artísticos o si pretendía evidenciar un enfoque desacralizador donde la historia literaria $y$, tal vez, no solo esta antología suya de poetas-vaqueros chilenos, se ubicaría en una frontera movediza y variable entre el chiste y el chisme.

A mi modo de ver, al presentar la poesía chilena de esta manera, Bolaño confirma que el campo cultural y, específicamente, el literario -el poético, en este caso- es una lucha, una pugna y una competencia continua entre sus participantes. Sin embargo, su visión extrema estas disputas percibiéndolas, literalmente, como riñas en un campo de batalla y la alusión histórica al duelo del "O.K. Corral" no es fortuita. Y tal como en sus obras mezcla ficción y biografía, trascendiendo esta carta y esta fecha, se diría que sus numerosos altercados y sus descalificaciones a otros escritores probarían y comprobarían esa perspectiva combativa. Para él, ese "oficio peligroso" de la literatura exigía arriesgarse en un constante desafío y responsabilidad que "... se parece mucho a la pelea de los samuráis, pero el samurái no pelea contra otro samurái, pelea contra un monstruo, generalmente sabe, además, que va a ser derrotado. Tener el valor, sabiendo previamente que vas a ser derrotado, y salir a pelear, eso es la literatura". 


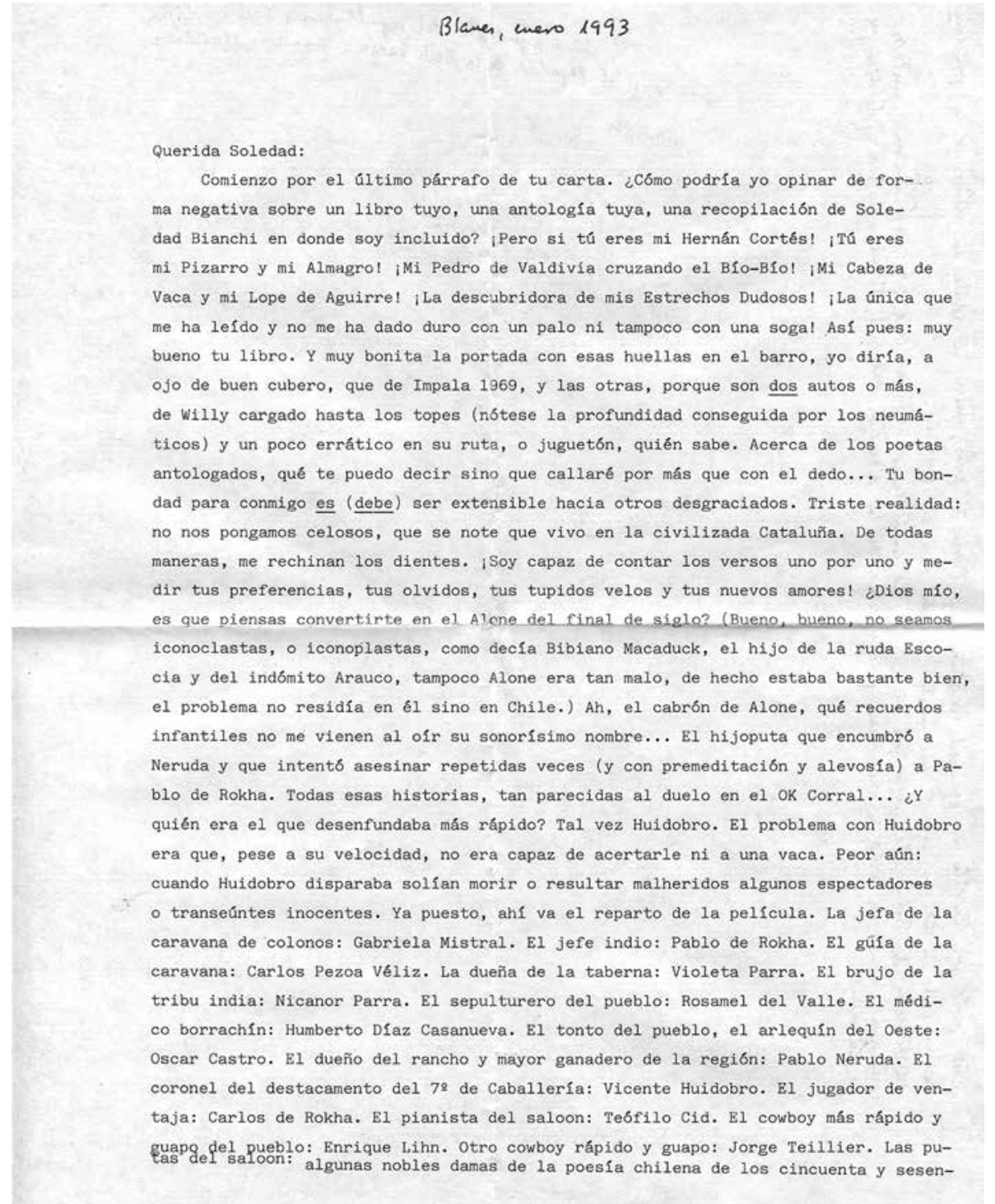




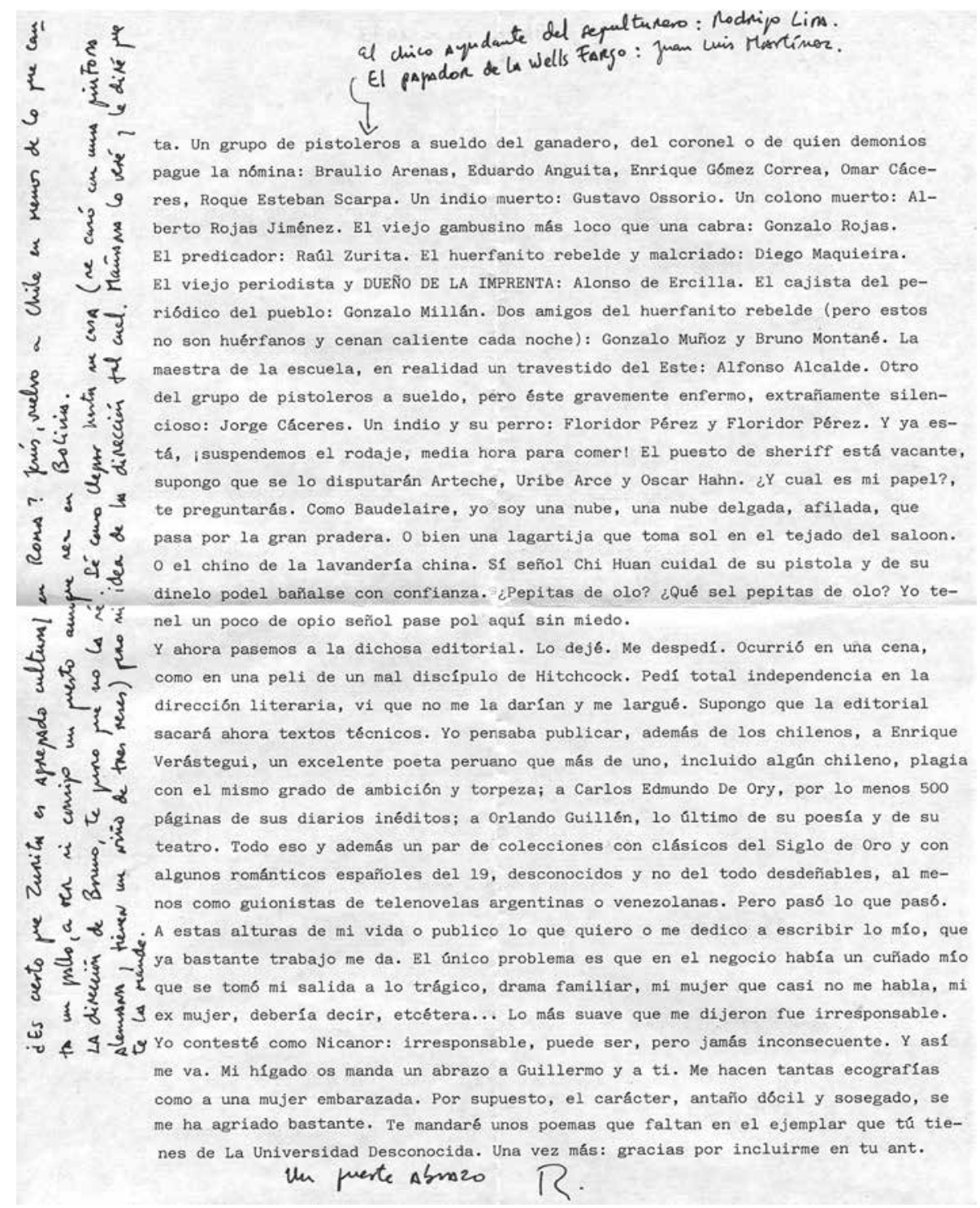

